\title{
Vegetarian diet and cobalamin deficiency: their association with tuberculosis
}

\author{
I CHANARIN, ELLA STEPHENSON \\ From the Department of Haematology, Medical Research Council Clinical Research Centre, Northwick Park \\ Hospital, Harrow
}

SUMmaRY To determine whether the high incidence of tuberculosis among Asiatic Indians in the United Kingdom was due to impaired killing of Mycobacterium tuberculosis by macrophages from patients deficient in cobalamin, a nutritional survey was carried out among 1187 Indians and the incidence of tuberculosis determined from medical records. The question asked was whether tuberculosis was significantly more common among life-long vegetarians compared with omnivores. The incidence of tuberculosis in vegetarians was 133 in 1000 and that in subjects on mixed diets 48 in 1000. These findings lend support to the hypothesis that dietary factors are of major importance in determining the susceptibility of Asiatic Indians to tuberculosis.

Cobalamin $\left(\mathrm{Cbl}\right.$, vitamin $\left.\mathbf{B}_{12}\right)$ is essential for normal health in man. It is required by all animals but is entirely absent from the plant kingdom, and a strictly vegetarian diet does not supply this nutrient. Fortunately, most vegetarian diets are less strict: some $\mathrm{Cbl}$ may be taken with milk and some may enter the diet via bacterial colonisation. Thus freshly harvested peanuts contain no $\mathrm{Cbl}$, but after storage $\mathrm{Cbl}$ appears with a bacterial or fungal population. ${ }^{1}$ Nevertheless, strict life-long vegetarians such as Hindu Indians consume minimal amounts of $\mathrm{Cbl}$. Low serum $\mathrm{B}_{12}$ concentrations are common as is nutritional megaloblastic anaemia due to $\mathrm{Cbl}$ deficiency. ${ }^{2}$ Mehta et al found that the mean $\mathrm{Cbl}$ concentration in 34 medical students on mixed diets was $366 \mathrm{pg} / \mathrm{ml}$; this was $121 \mathrm{pg} / \mathrm{ml}$ in 50 students who were vegetarians and less than $100 \mathrm{pg} / \mathrm{ml}$ in 25 . $^{3}$

A second important clinical feature in the Indian community in Britain is the high incidence of tuberculosis. A national survey of tuberculosis notification in England and Wales showed that when the incidence of tuberculosis in whites was given a value of 1 , that in Asiatic Indians was 38 , in West Indians of African origin 3 and in Africans $13 .{ }^{4}$ This is all the more remarkable as some of the Indian communities studied in the United Kingdom, such as that in Harrow, are affluent, with many belonging to the Registrar General's social classes I and II. ${ }^{2}$

A third factor concerns the role of $\mathrm{Cbl}$ in the killing of phagocytosed organisms. An impairment in bacterial killing by phagocytes among patients deficient in

Accepted for publication 18 February 1988
Cbl was first noted by Kaplan and Basford ${ }^{5}$ and was confirmed in a detailed study. ${ }^{6}$ Phagocytosis was normal but killing of ingested Staphylococcus aureus, oxygen burst, and luminol-amplified luminescence were impaired. This was present in all the Cbl deficient subjects studied whose red cell count was below 2.0 million $/ \mu$ l. Treatment with $\mathrm{Cbl}$ was followed by a return to normal phagocytic function one and a half to two and a half weeks later, a time consistent with the appearance in blood of a new generation of phagocytes arising from a haemopoietic stem cell.

The hypothesis put forward to explain the high incidence of tuberculosis in vegetarian Indians is that chronic $\mathrm{Cbl}$ deficiency results in a failure of macrophages to kill ingested mycobacteria. There is a second intriguing hypothesis that may be relevant. In $\mathrm{Cbl}$ deficiency there is a failure to convert methylmalonic acid to succinic acid as $\mathrm{Cbl}$ is a coenzyme in the enzyme methylmalonyl CoA-mutase. One of the components of the cell wall of $M$ tuberculosis is mycocerosic acid, and methylmalonic acid is the obligatory substrate for its synthesis. ${ }^{7}$ Can the increased concentrations of methylmalonic acid present in Cbl-deficient vegetarians provide a particularly favourable climate for the multiplication of $M$ tuberculosis?

The study reported here was set up to test the hypothesis that $\mathrm{Cbl}$ deficiency (for the reasons outlined above) was a factor in the high incidence of tuberculosis in a vegetarian population. Some 15000 Hindu Indians live in Harrow. Their traditional diet is vegetarian, but it has been influenced by British society, and many have broadened their diet to include foods of dairy or animal origin. The question asked 
was whether tuberculosis was more common in those whose diet remained largely vegetarian compared with those taking foods of animal origin.

\section{Study methods}

A questionnaire was sent to 2438 persons of Indian origin, over 30 years of age, and resident in Harrow. The names were taken from persons registered with local general practitioners and all were invited to provide information about diet and to give consent to allow their medical records to be seen. The questionnaire was written in English and Gujerati and a stamped return envelope was enclosed. The subjects were asked if they took milk, yoghurt, eggs, cheese, fish, chicken or meat and whether each was taken daily, several times a week, once a week or less, or never. A second copy of the questionnaire was sent to those who did not respond to the questionnaire within three weeks.

The diets were classified into groups (table 1); vegetarian where only some milk or yoghurt, or both, were taken; lactovegetarian where cheese or eggs, or both, were taken more than once a week; mixed where either fish, chicken, or meat was taken more than once a week. In addition, those who took some cheese (or eggs) or animal product once a week or less were grouped separately.

When demographical details were being obtained from general practitioner lists, a check was made of whether a firm diagnosis of tuberculosis had been recorded either by the doctor or in a hospital to which the patient had been referred. Notification of tuberculosis is mandatory in the United Kingdom. Thus the records of notification for tuberculosis maintained by the community physician were consulted. The only contact with the subjects of the study was by correspondence, and so more direct evidence of $\mathrm{Cbl}$ status such as the serum $\mathrm{Cbl}$ concentration was not available. Several thousand samples from Indian subjects in the Harrow area have been assayed over the past 15 years and the $\mathrm{Cbl}$ concentrations in 1000 consecutive records taken from the laboratory files in Indians were analysed. These are selected patients in so far as the requests were made in a clinical context. The Indian group constitute more than $10 \%$ of the adults in this community. The mean serum $\mathrm{Cbl}$ concentration in the Indians was $198 \mathrm{pg} / \mathrm{ml}$ compared with $334 \mathrm{pg} / \mathrm{ml}$ in a aged matched caucasian group: $54.6 \%$ of Indian samples were below the lower level of normality determined on a population taking a mixed diet compared with $11.7 \%$ in the caucasian group.

\section{Results}

Of the 2437 Indian subjects sent the questionnaire,
Table 1 Dietary habits of 1187 Indian subjects and prevalence of tuberculosis

\begin{tabular}{llll}
\hline Diet & $\begin{array}{l}\text { No of } \\
\text { subjects }\end{array}$ & Tubercle & $\begin{array}{l}\text { Tubercle/ } \\
1000\end{array}$ \\
\hline $\begin{array}{l}\text { Vegetarian (milk or yoghurt } \\
\text { only) }\end{array}$ & 158 & 21 & 133 \\
$\begin{array}{l}\text { Vegetarian + some dairy } \\
\text { produce* }\end{array}$ & 215 & 13 & 60 \\
$\begin{array}{l}\text { Vegetarian + some animal } \\
\text { produce* }\end{array}$ & 118 & 6 & 51 \\
$\begin{array}{l}\text { Lactovegetarian } \\
\text { Lactovegetarian + some }\end{array}$ & 291 & 25 & 86 \\
animal products* & 157 & 12 & 76 \\
Mixed diet & 248 & 12 & 48 \\
\hline
\end{tabular}

*Eaten less often than once a week.

1274 replied. Of these, 1187 completed the dietary survey and gave consent to further perusal of their medical records: 87 refused permission. The results of the dietary survey are shown in table 1 .

There were 158 subjects taking a vegetarian diet, the only source of animal protein being boiled milk taken with tea and some fermented milk (yoghurt) usually mixed into food. Lactovegetarians $(n=291)$ took cheese or eggs, or both products at least twice a week and 248 took a mixed diet defined by a meal containing fish, chicken, or meat not less than twice a week. Large numbers $(n=450)$ indicated that they took dairy produce or fish, chicken, or meat usually less often than once a week, and these people were subdivided into three further groups (tables 1 and 2).

In general, there were twice as many women as men among those taking a predominantly vegetarian diet. By contrast, there were twice as many men as women on a mixed diet. There were fewer female lactovegetarians. Those taking mixed diets tended to be younger (table 2).

Tables 1 and 2 also list the subjects with tuberculosis. The prevalence of tuberculosis in vegetarians was 21 of $158(133 / 1000)$ compared with 12 of 248 (48/ 1000 ) among those on mixed diets. This difference is highly significant $(p=0.0016$, Fisher exact test $)$. The incidence of tuberculosis was less in lactovegetarians (86 of 1000), and even those taking of dairy produce or meat less than once a week showed a lower incidence of tuberculosis than that seen in vegetarians, but this did not reach significance.

There were 49 men and 40 women among those with tuberculosis. Information on the site of infection was available in 62 patients (pulmonary $n=24$, lymph gland $n=24$, bone $n=8$, peritoneum $n=2$, liver $n=$ 2 , miliary $n=1$ and ileocaecal $n=1$ ).

There was a record of tuberculosis in the general practitioner file in 65 of the 1187 who responded to the questionnaire and in 81 of the 1163 patients who did not return the questionnaire. Although this difference 
Table 2 Age and sex of subjects completing dietary questionnaire

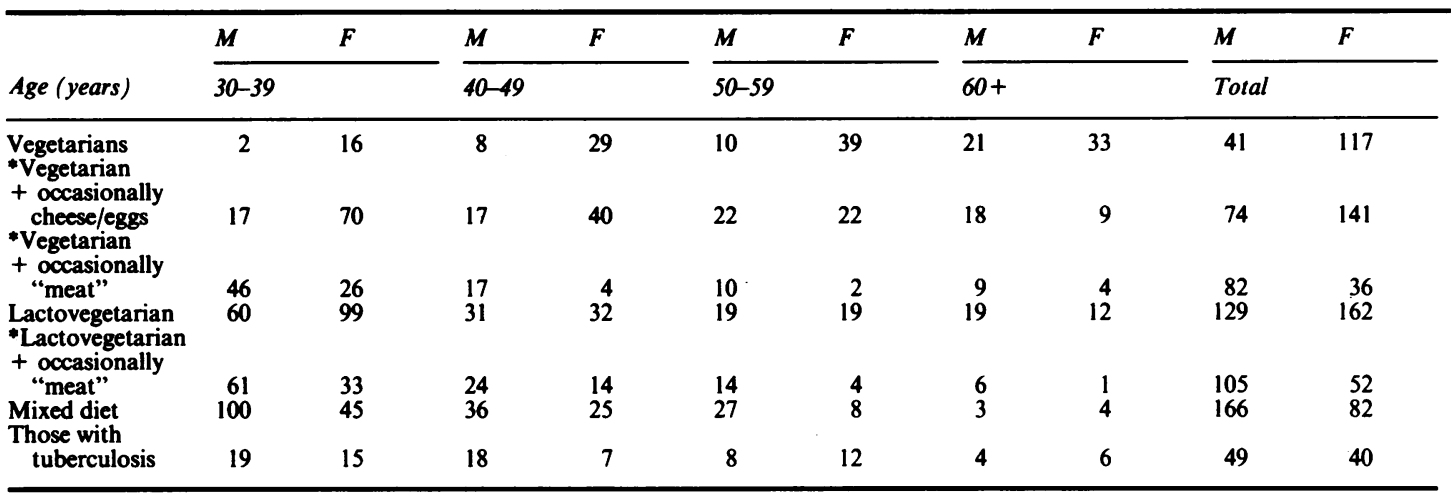

"cheese, eggs, or "meat" item generally less than once a week.

is not significant, it does raise the question whether some patients did not cooperate because they were unwilling to reveal a history of tuberculosis. The effect might be to reduce the recorded incidence of tuberculosis and lessen the difference between the vegetarian and other groups.

\section{Discussion}

The data show a significantly higher incidence of tubercle infection in those taking a relatively strict vegetarian diet compared with those taking a mixed diet. Subjects below the age of 30 were excluded as many of these will have grown up in the United Kingdom and usually have a vegetarian diet at home but a mixed diet at school, college, or work.

The response to the dietary questionnaire was only $50 \%$. The relatively low response is to some extent due to an unwillingness of the Gujerati community to reveal personal information and the return of the form was accompanied on several occasions by a request that the information might not be divulged to others. The slightly higher incidence of tuberculosis in the non-responders as judged by general practitioner records suggests the possibility that some did not respond because they were unwilling to divulge a history of tuberculosis. If so, that would underestimate the difference between the groups. The population studied represents a uniform racial and cultural group living under very similar urban circumstances and there were no obvious differences within the community that could increase the susceptibility to tuberculosis other than diet.

Although lack of $\mathrm{Cbl}$ seems to be the principal nutrient lacking in a vegetarian diet, clinically there is a high incidence of osteomalacia and iron deficiency. To some extent these are secondary to $\mathrm{Cbl}$ deficiency, which produces intestinal malabsorption, steatorrhoea, and impaired xylose absorption. ${ }^{2}$ The iron deficiency, however, is primarily related to poor availability of iron from a vegetarian diet. There is a high incidence of iron deficiency in the Indian community as judged from the high referral rate with this diagnosis to the haematology department. A recent study of 138 Indian patients with megaloblastic anaemia noted that 87 patients ( 53 women and 34 men) also had a history of iron deficiency or required the addition of iron for restoration of a normal blood picture. ${ }^{2}$ Twenty nine per cent of marrow samples lacked stainable iron on presentation, a rare finding in megaloblastic anaemia in caucasians. Iron deficiency is also associated with impaired ability of neutrophils to kill ingested bacteria ${ }^{8}$ and this lack of iron may well reinforce the effect of cobalamin deficiency in this population.

Impaired killing of ingested bacteria was a consistent feature in more severe megaloblastic anaemia due to $\mathrm{Cbl}$ deficiency. Our suggestion is that less severe defects, which are less easily demonstrable, were present in those with Cbl deficiency in the absence of obvious blood changes. Furthermore, although the studies on bacterial killing and the impaired oxygen burst were carried out with neutrophil polymorphs, macrophages also have the same mechanism of bacterial killing. It was far easier to harvest sufficient numbers of neutrophils for such studies than it was to obtain macrophages.

If this hypothesis is correct, it may be relevant to the vulnerability of populations to organisms other than $M$ tuberculosis, including leprosy. Testing the hypothesis further may prove difficult as only man develops megaloblastic anaemia as a result of $\mathrm{Cbl}$ deficiency. Similar biochemical consequences due to $\mathrm{Cbl}$ deficiency can be produced in other experimental animals and some develop neuropathy but in all these haemopoiesis remains normoblastic. Thus the impairment of cellular killing may be unique to man although further study is needed to confirm this. 
We thank Drs L M Adler, M Bodin, P D Carson, P F Ellis, S M A Farooqi, G W S Graham, R Jaffe, J M Justice, J Lister, D J Lloyd, H K Mangat, W D Martin, J K Nayar, A J S Nicholls, J E Noakes, G D S Pallawela, M Pandya, M Parker, J Parkes, B Peter, L Peter, E M Price, P Regunathan, M Rhodes, C Roberts (deceased), C Robinson, G Sado, N Samadi, O W Samuel, J K Sethi, S S Seyan, G E Shackleton, S Z Shah, F M Tomlinson, J Vyas, and $\mathrm{K} \mathbf{R}$ Walton for giving us access to their practice records and for their continued interest; Drs T Meade and A P Haines for their advice; Peter Clark for help with analysis of data; and Dr Clifford Jansz for access to patient records.

\section{References}

1 Ford J, Holdsworth ES. In: Smith EL, ed. Vitamin $B_{12}$, 3. London: Methuen, 1965:17.

2 Chanarin I, Malkowska V, O'Hea A-M, Rinsler MG, Price AB.
Megaloblastic anaemia in a vegetarian Hindu community. Lancet 1985;ii:1168-72.

3 Mehta BM, Rege DV, Satoskar RS. Serum vitamin $B_{12}$ and folic acid activity in lactovegetarians and nonvegetarian healthy adult Indians. Am J Clin Nutr 1964;15:77-84.

4 MRC Tuberculosis and Chest Diseases Unit National survey of tuberculosis notification in England and Wales 1978-9. Br Med $J$ 1980;281:895-8.

5 Kaplan SS, Basford RE. Effect of vitamin $B_{12}$ and folic acid deficiencies on neutrophil function. Blood 1976;47:801-5.

6 Skacel PO, Chanarin I. Impaired chemiluminescence and bacterial killing by neutrophils from patients with severe cobalamin deficiency. Br J Haematol 1983;55:203-15.

7 Rainwater DL, Kalattukudy PE. Fatty acid biosynthesis in Mycobacterium tuberculosis var bovis Bacillus CalmetteGuerin. J Biol Chem 1985;260:616-23.

8 Gross RL, Newberne PM. Role of nutrition in immunologic function. Physiological Review 1980;60:188-302.

Requests for reprints to: Dr I Chanarin, Department of Haematology, MRC Clinical Research Centre, Northwick Park Hospital, Watford Road, Harrow, Middlesex HAl 3UJ, England. 